\title{
DEVELOPMENT OF METHODOLOGY FOR CHARACTERIZATION OF SURFACE ROUGHNESS OF SOLID METALLIC SURFACES USING OIL SLIPPAGE METHOD
}

I. O. Ohijeagbon ${ }^{1}$, A. A. Adeleke ${ }^{\star}$, P. P. Ikubanni², T. A. Orhadahwe ${ }^{3}$, G. E. Adebayo ${ }^{1}$, A. S. Adekunle ${ }^{1}$, A. O. Omotosho ${ }^{4}$

'Department of Mechanical Engineering, University of Ilorin, Ilorin, NIGERIA.

2Department of Mechanical Engineering, Landmark University, Omu-Aran, NIGERIA ${ }^{3}$ Department of Mechanical Engineering, University of Ibadan, Ibadan, NIGERIA ${ }^{4}$ Department of Mechanical Engineering, Covenant University, Ota, NIGERIA *e-mail: adeleke.kunle@ymail.com

The study employed the phenomenon of friction between liquid droplets and solid metallic surfaces in surface roughness analysis of engineering materials. Five samples of mild steel plate were prepared to different degrees of surface roughness by facing operation. The sample surfaces were analysed to determine the roughness parameters (mean roughness, root mean square roughness, roughness skewness, and roughness kurtosis) and friction coefficient of the surfaces. Oil droplet sliding velocity was determined using the oil slippage test. The friction coefficient of the surfaces increased with increasing roughness parameter which varied from $26.334 \mu \mathrm{m}$ at friction coefficient $=0.63$ to $13.153 \mu \mathrm{m}$ at friction coefficient $=0.46$. The results from oil slippage test showed that the sliding velocity of the oil drop decreased as the friction coefficient of samples increased. At an inclination angle of $30^{\circ}$, sliding velocity varied from $0.51 \mathrm{~cm} / \mathrm{s}$ at friction coefficient $=0.63$ to $0.92 \mathrm{~cm} / \mathrm{s}$ at friction coefficient $=0.46$. Some of the samples exhibited a deviation in the trend of relationship between friction coefficient and sliding velocity which resulted from the variation in peak height of roughness between the sample surfaces. Oil slippage method predicts the surface behaviours of materials based on their surface parameters.

Keywords: Dry friction, image analysis, oil slippage, surface profilometry, surface roughness parameters. 
Surface roughness is a term used to describe closely packed irregularities, the height, width, and direction that create the prevalent pattern on surfaces. These irregularities can be attributed to the production process. The impact of surface roughness on the behaviours of systems has been considered critical in the characterisation of engineering surfaces for industrial and commercial applications [1], [2]. Castillejos and Tania [3] show that thermal resistance of continuous casting mould slag depends on the surface roughness. The joining strength of two surfaces increases with an increase in surface roughness [4]. By implication, surface roughness has a positive influence on the adhesion behaviour of two surfaces. Conversely, surface roughness has been proven to have detrimental effect on fatigue loading capacity of metals. The notch-like features of rough surfaces serve as stress epicentres and crack initiation sites, thereby reducing the fatigue strength of the material [5]possible applications are direct production of casting molds, tools or turbine blades with internal cooling channels for an optimized cooling efficiency. A disadvantage of the technology is the process-inherent surface roughness, which is critical especially under fatigue loading conditions. Since internal surfaces often cannot be smoothened due to limited accessibility, the objective of this study is to assess the fatigue properties of Ti-6Al-4V samples designed with internal axial channels featuring a rough as-built surface. Samples with various diameters and numbers of channels have been tested not always exhibiting a deterioration of the fatigue performance compared to solid samples. Subsequent fractography by scanning electron microscopy revealed distinct failure mechanisms. Besides the fatigue crack initiation on features of the unmodified internal surfaces, residual porosity in the bulk, i.e. lack-of-fusion defects, keyhole defects and gas pores, respectively, could be identified as crack origin. Relatively low scatter of fatigue lives found is attributed to rapid crack initiation and, thus, the dominant influence of the (micro-. Similarly, the frictional force between two moving parts in contact depends largely on the texture of their surfaces. There are two main explanations for the phenomenon of friction: the adhesion and abrasion theories. Both of these theories are based on the integrity of the surfaces in contact. Therefore, the effects of friction between sliding surfaces depend greatly upon the surface roughness of contact surfaces. Surface roughness could therefore be considered as having a considerable influence on the long-term sustainability both when considering the properties of the finished product as well as during production [6], [7].

Lubricants are used to mitigate the adverse effect of friction, such as achieving lubricity and elongating the life span of machine components during application. The use of solid lubricants as additive to oils and grease is gaining global attention. Oshita et al. [8] reported that the roughness of the surfaces of metal substrates had a great influence on the lubrication performances of solid lubricants during cold forging operations. It was observed that the anti-seizure properties of these solid lubricant substrates were improved significantly as their surfaces became more roughened as a result of improved adhesion strength between the lubricant and the rough surface. Surface roughness plays an important role in determining how objects interact with each other. It is often a good predicting factor of the performance of mechanical 
components [9]. For instance, it influences the rate of water absorption in stainless steel [10] and lowers the quenching time of hot surfaces during cooling [11].

Hence, it is of great importance to be able to describe the topography of material surfaces before the use of such materials in various engineering applications [12]. Researchers have shown several methods for investigating surface roughness parameters, which include the use of atomic force microscopy (AFM), power spectral density (PSD), optical profilometry, surface profiler and image analysis [13]-[15]. The use of image analysis as a technique in observing surface characteristics of materials is gaining wide acceptance. This implies that with the use of suitable image analytics software, the profile characteristics of surfaces can be measured electronically [16], [17].

The conventional method of surface roughness analysis involves the use of dry friction contact and wear testing, which may require complex tooling and is time consuming [18], [19]. The study explored the phenomenon of friction between a solid surface and a liquid droplet in surface roughness analysis. In the present study, a new method was developed in which oils of known viscosities were made to slide over solid metallic surfaces and the friction properties of the metallic surfaces were predicted from the interaction between the oils and the surfaces.

\section{EXPERIMENTAL}

\subsection{Material Preparation}

The experimental samples consist of five plates of dimensions cut from mild steel which was obtained from Ilorin Metropolis, Nigeria. The samples were prepared to different degrees of surface roughness by facing operation performed on a Lathe machine using a carbide tip boring tool at different speeds $(48,66,92,132$, and 185

\subsection{Surface Profilometry and Analysis}

The prepared surfaces of the samples were scanned photographically with the aid of a Canon EOS 5D Mark IV Kit camera. The line profiling and surface profile analy- rpm) and depths of cut $(2.5,2.0,1.5,1.0$, and $0.5 \mathrm{~mm}$ ). Standard roughness parameters are: arithmetical mean deviation of the profile $\left(R_{a}\right)$, ten point height of irregularities $\left(R_{z}\right)$, maximum height of the profile $\left(R_{\max }\right)$, maximum height of profile peak $\left(R_{p}\right)$, and profile bearing length ratio $\left(t_{p}\right)$ [20]. Table 1 shows the machining details of the samples.

Table 1. Machining Details of Samples

\begin{tabular}{|l|c|c|}
\hline Sample & Depth of Cut $(\mathrm{mm})$ & Cutting Speed (rpm) \\
\hline 1 & 2.5 & 48 \\
\hline 2 & 2.0 & 66 \\
\hline 3 & 1.5 & 92 \\
\hline 4 & 1.0 & 132 \\
\hline 5 & 0.5 & 185 \\
\hline
\end{tabular}




\subsection{Investigation of Solid Metallic Surfaces Using the Dry Friction Method}

Experimental set-up for establishing the static friction coefficient projected specially for this investigation is shown in Fig. 1 (a and $b$ ). The schematic representation of the set-up is shown in Fig. 2. The test sample was placed on an inclined plane apparatus, as shown in Fig. 1. A solid block of known and recorded mass $(m)$ was kept on the surface of the plane. The angle of inclination was adjusted until the block just began to move. The angle at which the first movement was observed was recorded, which indicated static friction [21]. The coefficient of static friction was calculated using Eqs. (1)-(3). The vertical and horizontal forces were balanced to obtain Eqs. (1) and (2).

$$
\begin{aligned}
& \mathrm{N}=\mathrm{mg} \cos \theta, \\
& F=\mathrm{mg} \sin \theta,
\end{aligned}
$$

Coefficient of static friction,

$\mu=\frac{\mathrm{F}}{\mathrm{N}}=\frac{\mathrm{mg} \sin \theta}{\mathrm{mg} \cos \theta}=\tan \theta$,

where F - frictional force in Newton; $\mathrm{m}$ mass of the body in $\mathrm{kg} ; \mathrm{g}$ - gravitational acceleration in $\mathrm{m} / \mathrm{s}^{2} ; \mathrm{N}$ - normal force exerted on the body by the plane due to gravity and $\theta$ - the angle of inclination. The nature of the relationship between roughness parameter $\left(R_{a}\right)$ and the static coefficient of friction $(\mu)$ was investigated graphically.
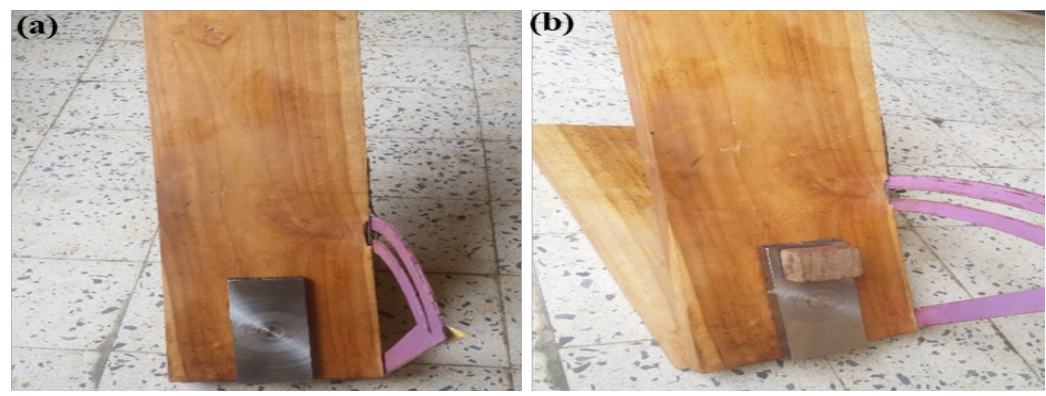

Fig. 1. Set up for dry friction investigation: (a) without the solid block; (b) with the solid block.

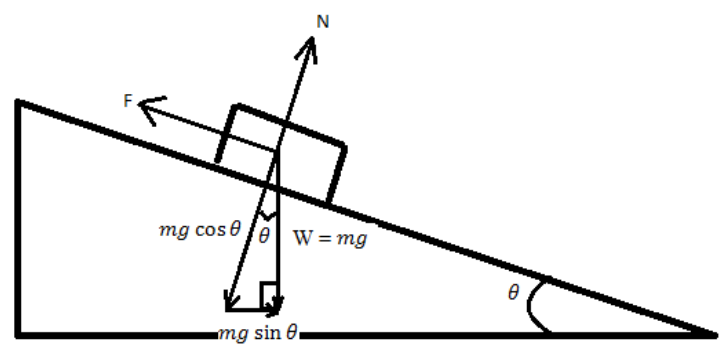

Fig. 2. Schematic representation of the dry friction inclined plane set-up.

\subsection{Investigation of Solid Metallic Surfaces Using the Oil Slippage Method}

An oil drop whose centre of mass moved with a steady velocity, $u$, down a plane inclined at an angle, $\alpha$ with the hori- zontal as shown in Fig. 3 was investigated. The fluid formed a steady stream moving downwards under the action of gravity. The 
velocity distribution of different material properties and different inclination angles was examined. The impact of volume of drop and angle of inclination on drop sliding velocity were determined. The oil drop has the density, $\rho$, the surface tension, $\sigma$, and the viscosity, $\eta$. It was assumed that was dependent on $\sigma, \eta$, and $\rho$ [22]. Figure 4 shows the set up for the oil slippage test.

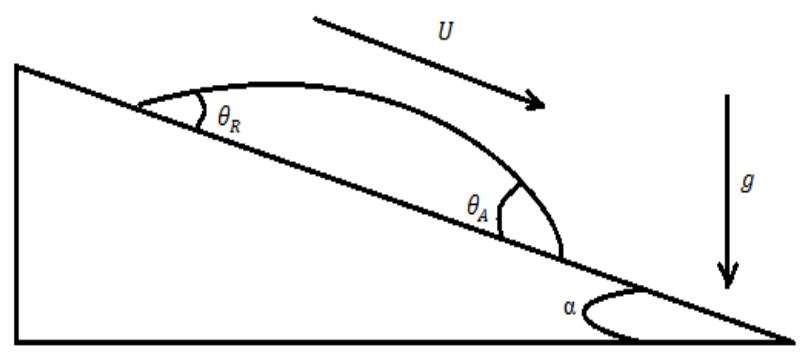

Fig. 3. Schematic diagram of a sliding drop down an inclined plane.

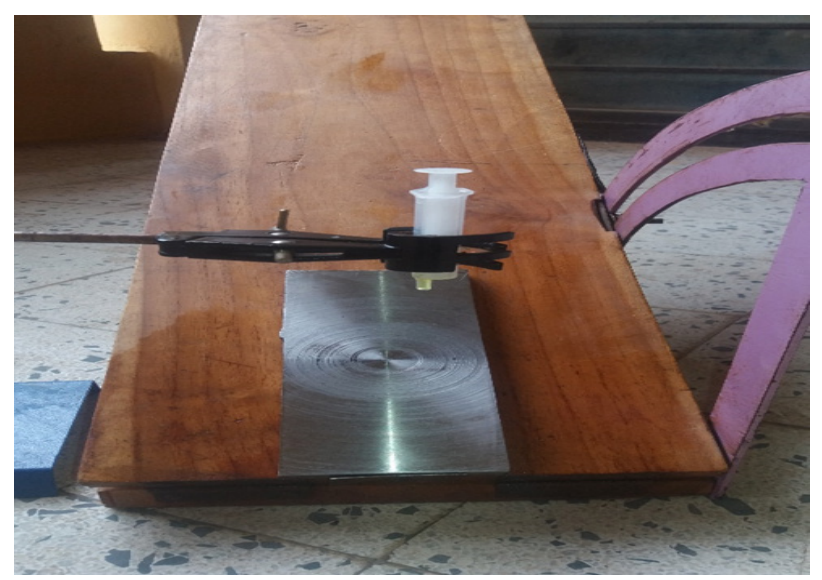

Fig. 4. Set-up for oil slippage test.

LUBCON Super XV 20W50 Oil of $165.5 \mathrm{mPa}$.s viscosity was used to vary the fluid dynamics and interfacial properties in this study. The experiments were carried out under standard laboratory conditions. The inclined plane was set up as shown in Fig. 4. The test sample was placed on the plane and set to various angles of inclination to investigate the velocity of oil drop. A known volume of oil is dropped on the plane and was allowed to slide down a marked distance $(s)$ of $10 \mathrm{~cm}$ across the centre of the test material. The marked distance is $5 \mathrm{~cm}$ towards the centre and $5 \mathrm{~cm}$ away from the centre. Hence, an average distance of 5 $\mathrm{cm}$ was taken into account assuming the test material has a uniform surface texture over the average $5 \mathrm{~cm}$ distance. The time taken $(t)$ for the drop to travel through the marked distance $(s)$ was recorded and the velocity $(u)$ of the oil drop down the experimental plane was calculated by Eq. (4):

$\mathrm{u}=\frac{\mathrm{s}}{\mathrm{t}}$.

The investigation was taken further by varying the volume of the oil drop on the sample surfaces to investigate the indepen- 
dent effect of each of these parameters on the sliding velocity of the drop down the plane. The correlation between roughness parameter $\left(R_{a}\right)$, the coefficient of friction $(\mu)$ and the sliding velocity of oil drop is done by making a plot of the coefficient of friction against the sliding velocity. A mathematical relationship between coefficient of dry friction $(\mu)$ and sliding velocity $(u)$ due to oil slippage was deduced graphically.

\section{RESULTS AND DISCUSSION}

\subsection{Surface Profilometry}

The line profiling and surface profile analysis were done using Image $\mathrm{J}$ software version 1.4.3.67. Figures 5-9 show the representative line profiles of sample surfaces. Arithmetic mean deviation of the roughness profile $\left(R_{a}\right)$ was calculated for all the line profiles. The results obtained from surface profilometry reveal the important parameters to be considered in this study. The roughness parameters are captured in Table 2. It reveals that the values of mean roughness $\left(R_{a}\right)$ reduced from $26.334 \mu \mathrm{m}$ in sample 1 ( $2.5 \mathrm{~mm}$ depth) to $13.153 \mu \mathrm{m}$ in sample $5(0.5 \mathrm{~mm}$ depth). This clearly depicts that the surface roughness depends on the depth of cuts made on the surface.
However, the roughness kurtosis increased from $3.001 \mu \mathrm{m}$ in sample 1 to $7.177 \mu \mathrm{m}$ in sample 5, which demonstrated that as the depth of cut reduced, there was a reduction in the noise level of the image obtained thereby leading to a sharp curve with short tail [23]. Similarly, the roughness skewness, which is a measure of the direction where the bulk of the values lie either to the right or the left of the mean also increased from $1.579 \mu \mathrm{m}$ in sample 1 to $2.289 \mu \mathrm{m}$ in sample 5. This shows that as the cutting depth decreases, the bulk of the values of the probability density function are to the right of the mean [24].
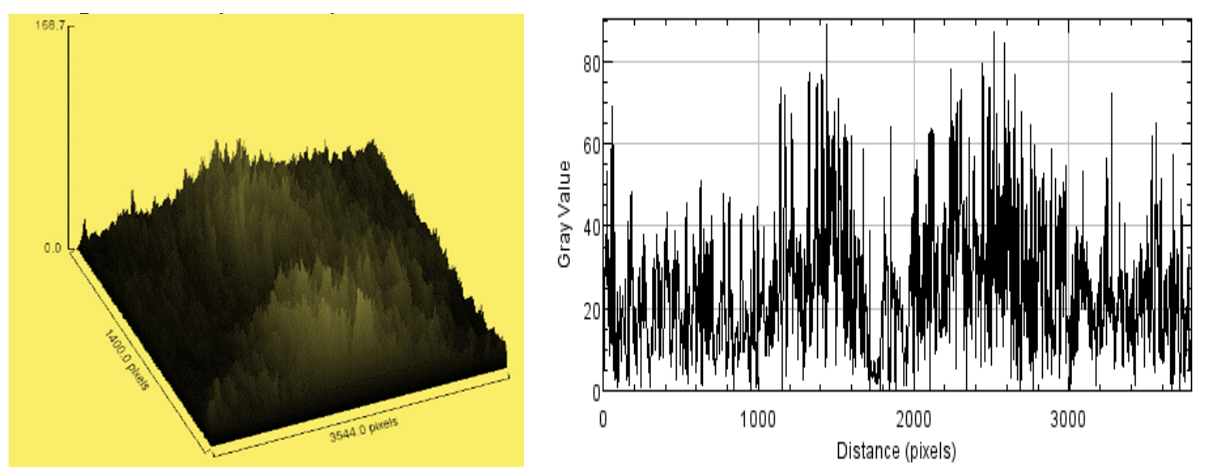

Fig. 5. Surface roughness $R_{a}$ for sample 1 . 

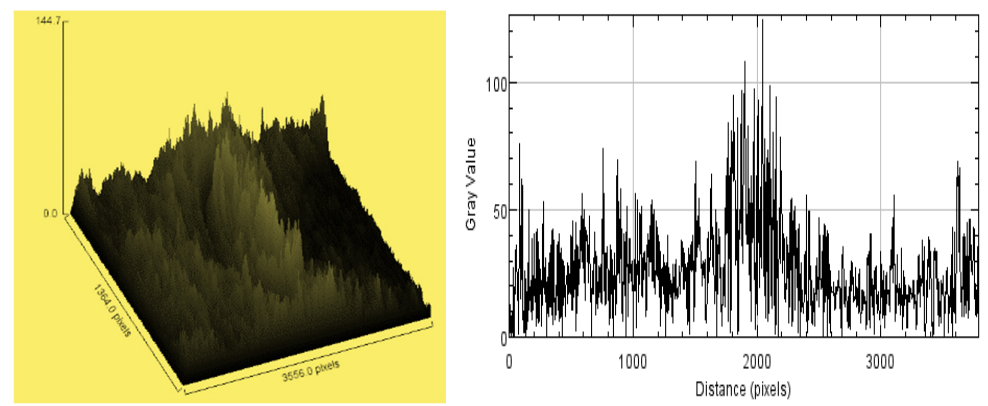

Fig. 6. Surface roughness $R_{a}$ for sample 2 .
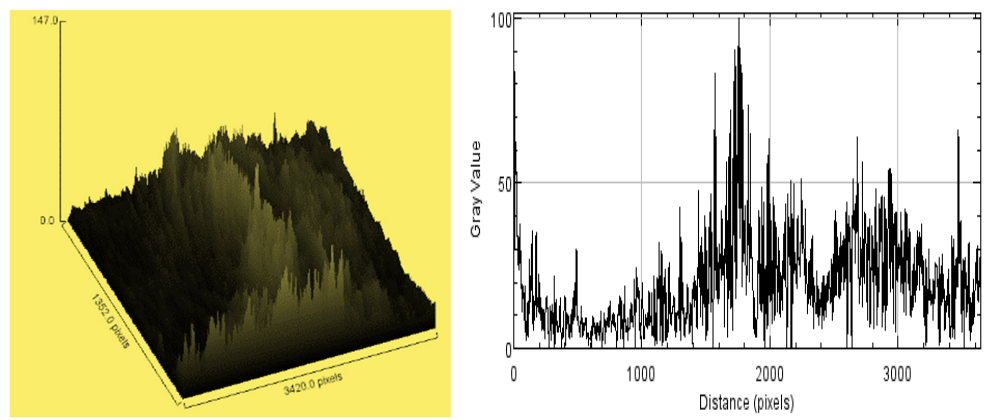

Fig. 7. Surface roughness $R_{a}$ for sample 3 .
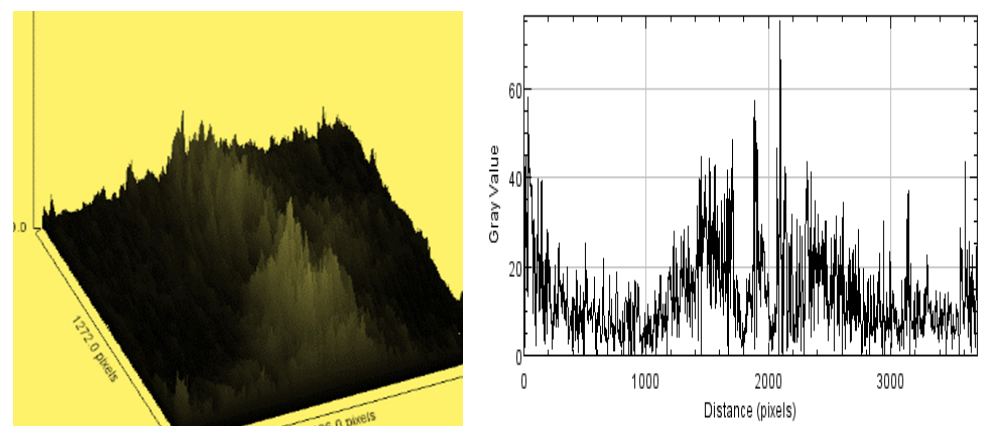

Fig. 8. Surface roughness $R_{a}$ for sample 4 .
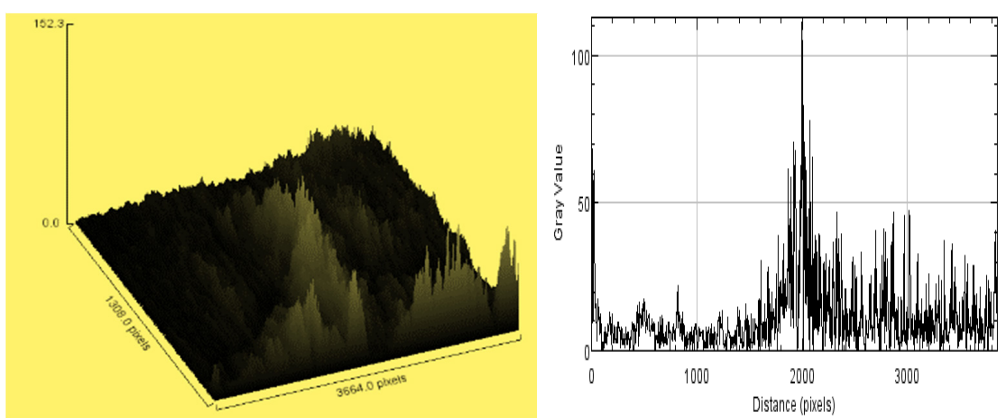

Fig. 9. Surface roughness $R_{a}$ for sample 5 . 
Table 2. Roughness Parameters

\begin{tabular}{|l|c|c|c|c|c|c|c|}
\hline Sample & $R_{q}(\mu \mathrm{m})$ & $R_{a}(\mu \mathrm{m})$ & $R_{s k}(\mu \mathrm{m})$ & $R_{k u}(\mu \mathrm{m})$ & $\begin{array}{c}\text { Highest } \\
\text { Peak }(\mu \mathrm{m})\end{array}$ & $\begin{array}{c}\text { Lowest } \\
\text { Valley }(\mu \mathrm{m})\end{array}$ & $\begin{array}{c}\text { Total } \\
\text { Height }(\mu \mathrm{m})\end{array}$ \\
\hline 1 & 32.172 & 26.334 & 1.579 & 3.001 & 168.667 & 0 & 168.667 \\
\hline 2 & 27.680 & 22.698 & 1.572 & 3.045 & 144.667 & 0 & 144.667 \\
\hline 3 & 25.788 & 20.696 & 1.697 & 3.648 & 147.000 & 0 & 147.000 \\
\hline 4 & 21.458 & 16.278 & 1.933 & 4.862 & 151.670 & 0 & 151.670 \\
\hline 5 & 18.474 & 13.153 & 2.289 & 7.177 & 102.333 & 0 & 102.333 \\
\hline
\end{tabular}

$* R_{a}$ - mean roughness, $* R_{q}-$ root mean square roughness, $* R_{s k}-$ roughness skewness and $* R_{k u}-$ roughness kurtosis

\subsection{Analysis of Solid Metallic Surfaces Using the Dry Friction Inclined Plane Method}

The experimental values obtained from the dry friction test of sample surfaces are shown in Table 3. This is a compilation of the average values of inclination angles and static coefficients of friction. The values varied from $26.334 \mu \mathrm{m}$ at $\mu_{1}=0.63$ to $13.153 \mu \mathrm{m}$ at $\mu_{5}=0.46$. The roughness values increased as friction coefficient increased. Figure 10 elaborates the variation of arithmetic mean deviation of the roughness profile $\left(\mathrm{R}_{\mathrm{a}}\right)$ with respect to the friction coefficient during dry sliding. The plot shows a positive slope with increasing uphill trend. The profilometric feature analysis of the sample surfaces established the correlation between coefficient of friction and surface roughness. It affirms that coefficient of friction increases with an increase in surface roughness parameter [19].

Table 3. Results of Dry Friction Inclined Plane Method

\begin{tabular}{|l|c|c|c|c|}
\hline Sample & $\begin{array}{c}\text { Angle of Inclination } \\
\left(\theta^{\circ}\right)\end{array}$ & $\begin{array}{c}\text { Friction Coefficient } \\
\mu_{\mathrm{S}}\end{array}$ & $\begin{array}{c}\text { Surface Roughness } \\
\mathrm{R}_{\mathrm{a}}(\mu \mathrm{m})\end{array}$ & $\begin{array}{c}\text { Highest Peak } \\
(\mu \mathrm{m})\end{array}$ \\
\hline 1 & 32.33 & 0.63 & 26.33 & 168.67 \\
\hline 2 & 30.83 & 0.60 & 22.70 & 144.67 \\
\hline 3 & 30.00 & 0.58 & 20.70 & 147.00 \\
\hline 4 & 27.67 & 0.52 & 16.28 & 151.67 \\
\hline 5 & 24.83 & 0.46 & 13.15 & 102.33 \\
\hline
\end{tabular}

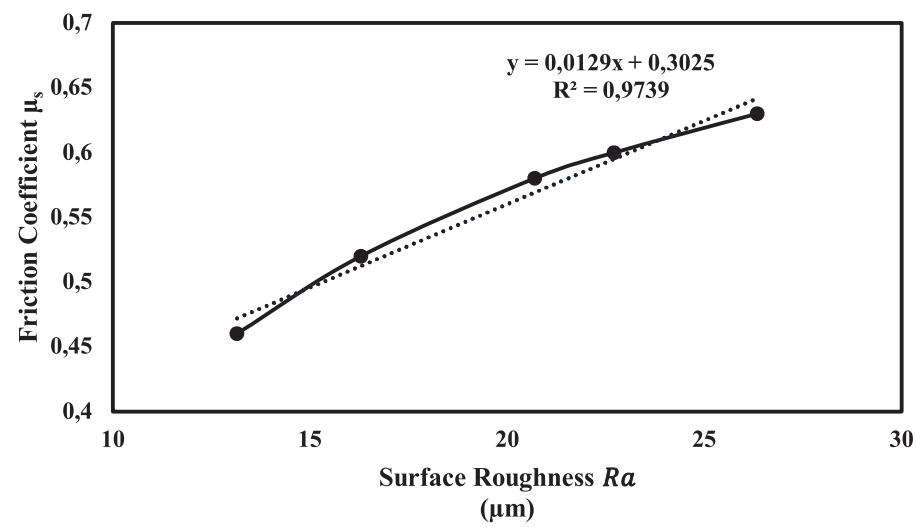

Fig. 10. Dependence of friction coefficient on surface roughness. 


\subsection{Analysis of Solid Metallic Surfaces Using Oil Slippage Method}

The graphs of the experimental values obtained from the oil slippage test of sample surfaces are shown in Figs. 11 and 12. Figure 11 shows the graphical relationship between sliding velocity and angle of inclination. It was observed that at higher angles of inclination than the repose angles obtained from the dry friction test, the convergence in the values of velocity of all five samples became greater (the values of velocity started getting close). It could be opined that at greater inclination angles than the angle of repose obtained for a particular sample, the effect of surface roughness over the sliding velocity of oil drop reduced. Oshita et al. [8] posited that an increase in surface roughness led to an increase in adhesion strength between the oil and rough surface, which might result in a decrease in the sliding velocity of the oil.
However, the results of this study reveal that the sliding velocity of oil drops increases with greater values of inclination angle. This is due to the reduction in the pinning effect of the roughness ridges over the oil drop as the inclination angle increases, leading to a greater sliding velocity of the oil drop as it slides over the surface. A deviation in trend was observed from the plots for each sample at inclination angles close to or greater than the repose angles obtained from dry friction test. This can mean that the oil slippage test has its critical angle of operation. To establish the nature of the relationship between the volume of oil drop and the sliding velocity of the drop, values of sliding velocity obtained from oil slippage test of each sample surface were plotted against the set volumes of oil drop, as shown in Fig. 12.

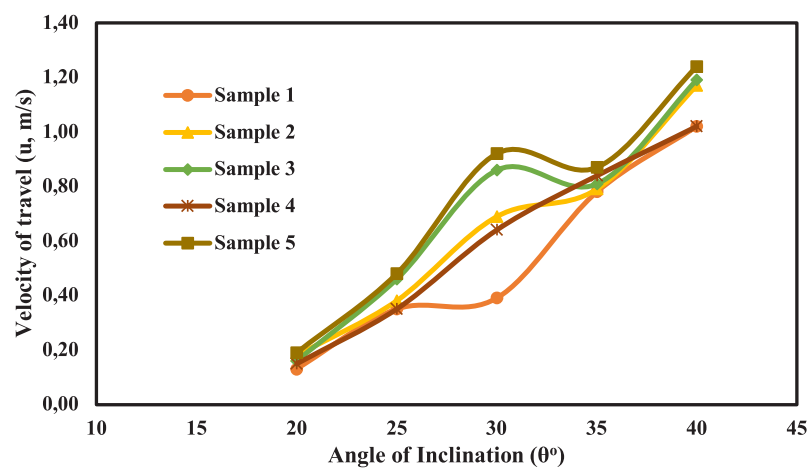

Fig. 11. Relationship between velocity of travel and angle of inclination.

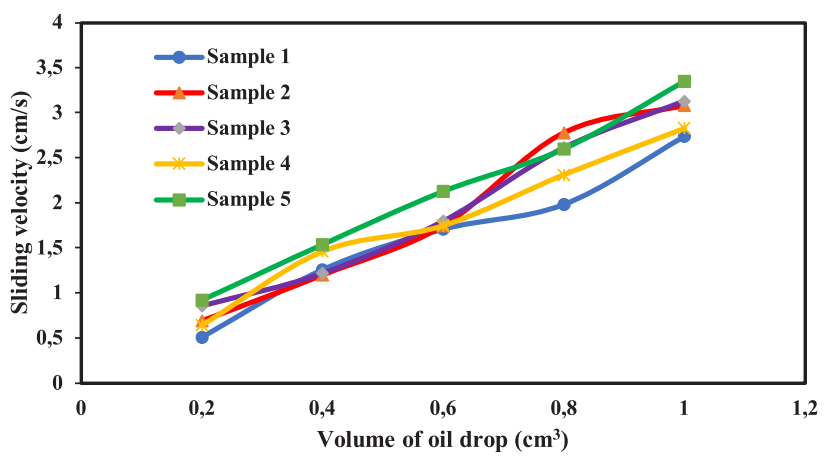

Fig. 12. Relationship between sliding velocity and volume of oil drop. 
The results of experimental investigations reveal that the sliding velocity of oil drops increases with greater values of oil drop volume. This is because the forces acting on the oil drop as it slides down the surface depend upon the volume of the oil drop. The results of experimental investigations depict that the sliding velocity of oil drops increases as friction coefficient values decrease. The oil droplet encountered ridges of varying heights over each of the surfaces which affected the sliding velocity of the oil drop. It can be asserted that an increment in the values of dry friction coefficient could mean a decrement in the values of velocity. However, by careful observation of the data set obtained from the oil slippage test, sample 4 showed an unusual trend.

Despite the low value of friction coefficient, the sliding velocity appears lower than expected. As seen from the surface profilometry results, the highest peak value for sample 4 is only lower to that of sample 1 . The oil drop has to travel through higher surface ridges in sample 4 than in samples 2, 3 and 5.
Sample 3 has a higher peak value than sample 2, but the difference between their highest peak values are almost negligible. More so, at some inclination angles, the roughness ridges of sample 3 are more active than that of sample 2. It could be said that the roughness height of the surface is better taken into account with the oil slippage test method than in the dry friction method.

Mathematical model for the relationship between friction coefficient and sliding velocity was determined graphically from the plot in Fig. 13 and shown in Eq. (5). The mathematical relationship shows that if the sliding velocity is ascertained from oil slippage method, the coefficient of friction can be calculated for mild steel using the relationship. Hence, there would be no need for the conventional dry friction method. However, it is worth noting that the sliding velocity depends on certain parameters such as volume of drop and angle of inclination.

$\mathrm{v}=0.0036 \mu^{2}+0.0016 \mu+0.774$

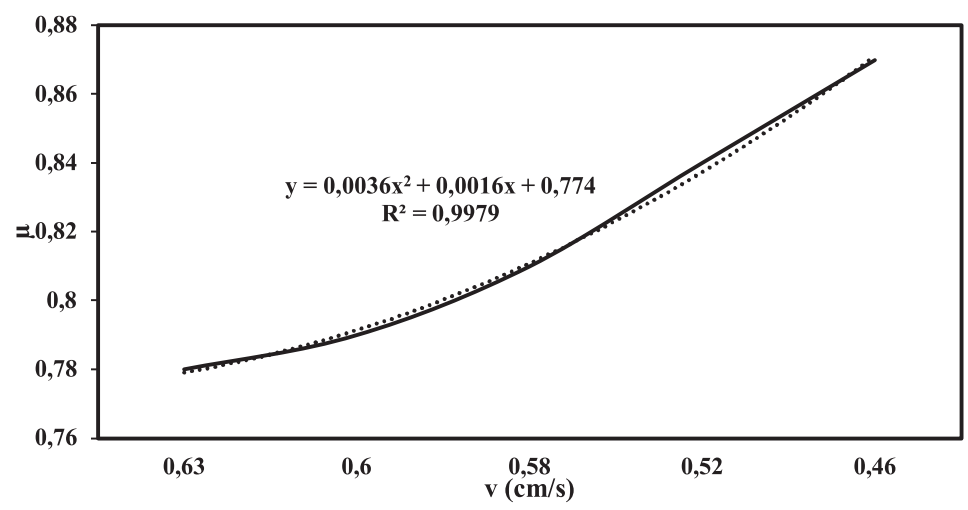

Fig. 13. Sliding velocity vs coefficient of dry friction.

\section{CONCLUSION}

Contact surface roughness has direct influence on the static friction coefficient. Generally, it can be stated that the static friction coefficient increases with surface roughness parameters. The machining processes employed in the preparation of 
sample surfaces result in the difference in static friction coefficient values of the surfaces. The results of the study have also shown that there is a functional dependence between the friction coefficient and the sliding velocity of oil drop down a solid metallic surface. It should be noted that several other parameters affect the sliding velocity of the oil drop. It is important to pay close attention to these parameters. The relationship between the friction coefficient and the sliding velocity of oil drop is a good predicting factor in surface roughness characterisation studies. The oil drop method of investigation proves to be the development of the conventional dry sliding method as it puts all parameters that describe the texture of a surface into better consideration.

Subsequent study should examine a mathematical relationship between sliding velocity of the oil slippage method and coefficient of dry friction based on the angles of inclination in order to be able to predict the coefficient of dry friction from performing only the oil drop experiment, thereby eliminating the need for dry friction method.

\section{REFERENCES}

1. Vazquez-Calvo, C., Alvarez De Buergo, M., Fort, R., \& Varas-Muriel, M.J. (2012). The Measurement of Surface Roughness to Determine the Suitability of Different Methods for Stone Cleaning. J Geophys Eng, 9, S108-17. https://doi.org/10.1088/17422132/9/4/S108.

2. Al-Samarai, R.A.H., Ahmad, K.R., \& Al-Douri, Y. (2012). Evaluate the Effects of Various Surface Roughness on the Tribological Characteristics under Dry and Lubricated Conditions for Al-Si Alloy. $J$ Surf Eng Mater Adv Technol, 2, 167-73. https://doi.org/10.4236/jsemat.2012.23027.

3. Castillejos, E.A.H., \& Tania, M.F.F. (2019). Characterization of Roughness, Porosity and Thermal Resistances of Continuous Casting Mold Slag Layers Devitrified and Crystallized in Laboratory. Metall Mater Trans B Process Metall Mater Process Sci, 50 (24), 36-53. https://doi.org/10.1007/ s11663-019-01655-4.

4. Altan, T., \& Celik, S. (2020). Effect of surface roughness of the metallic interconnects on the bonding strength in solid oxide fuel cells. Int J Hydrogen Energy, 1-12. https:// doi.org/10.1016/j.ijhydene.2020.03.136.

5. Günther, J., Leuders, S., Koppa, P., Tröster, T., Henkel, S., Biermann, H., \& Niendorf, T. (2018). On the effect of internal channels and surface roughness on the high-cycle fatigue performance of Ti-6Al-4V processed by SLM. Mater Des, 143, 1-11. https://doi. org/10.1016/j.matdes.2018.01.042.

6. Bera, B. (2014). Generalized adhesion theory of friction. In Asiat. Conf. (pp. 2-4), 17-20 February 2014, Agra, India.

7. Anvari, A. (2016). Friction coefficient variation with sliding velocity in copper with copper contact. Period Polytech Mech Eng, 60, 137-41. https://doi.org/10.3311/ PPme.8429.

8. Oshita, K., Yanagi, M., Okada, Y., Komiyama, S., \& Wang, Z. (2017). Effect of surface roughness on improved lubricity under an ironing condition using a synthetic mica-organic intercalation compound. Tribol Online,12, 193-202. https://doi. org/10.2474/trol.12.193.

9. Zhai, C., Gan, Y., Hanaor, D., Proust, G., \& Retraint, D. (2016). The Role of Surface Structure in Normal Contact Stiffness. Exp Mech, 56, 359-68. https://doi.org/10.1007/ s11340-015-0107-0.

10. Manaf, N.D., Fukuda, K., Subhi, Z.A., \& Mohd-Radzi, M.F. (2019). Influences of surface roughness on the water adsorption on austenitic stainless steel. Tribol Int, 136, 75-81. https://doi.org/10.1016/j. triboint.2019.03.014. 
11. Deendarlianto, A., Takata, Y., Kohno, M., Hidaka, S., Wakui, T., Majid, A.I., ... \& Widyaparaga, A. (2016). The effects of the surface roughness on the dynamic behavior of the successive micrometric droplets impacting onto inclined hot surfaces. Int $J$ Heat Mass Transf, 101, 1217-26. https://doi. org/10.1016/j.ijheatmasstransfer.2016.05.132.

12. Menezes, P.L., \& Kailas, S.V. (2016). Role of surface texture and roughness parameters on friction and transfer film formation when UHMWPE sliding against steel. Biosurface and Biotribology, 2, 1-10. https://doi. org/10.1016/j.bsbt.2016.02.001.

13. Feng, D., Shen, M., Peng, X.D., \& Meng, X.K. (2017). Surface Roughness Effect on the Friction and Wear Behaviour of Acrylonitrile-Butadiene Rubber (NBR) under Oil Lubrication. Tribol Lett, 65, 1-14. https://doi.org/10.1007/s11249-016-0793-5.

14. Jacobs, T.D.B., Junge, T., \& Pastewka, L. (2017). Quantitative Characterization of Surface Topography Using Spectral Analysis. Surf Topogr Metrol Prop, 5, 1-10. https://doi.org/10.1088/2051-672X/aa51f8.

15. Erinosho, M.F., Akinlabi, E.T., \& Johnson, O.T. (2017). Characterization of Surface Roughness of Laser Deposited Titanium Alloy and Copper Using AFM. Appl Surf Sci, 435, 393-7. https://doi.org/10.1016/j. apsusc.2017.11.131.

16. Orhadahwe, T.A., Adeleke, A.A., Aweda, J.O., Ikubanni, P.P., \& Odusote, J.K. (2020). Microstructural Image Analyses of Mild Carbon Steel Subjected to a Rapid Cyclic Treatment. J Chem Technol Metall, 55, 198-209.

17. Adeleke, A.A., Ikubanni, P.P., Orhadahwe, T.A., Aweda, J.O., Odusote, J.K., \& Agboola, O.O. (2019). Microstructural Assessment of AISI 1021 Steel under Rapid Cyclic Heat Treatment Process. Results Eng; 4, 1-4. https://doi.org/10.1016/j. rineng.2019.100044.
18. Jiang, H., Browning, R., Fincher, J., Gasbarro, A., Jones, S., \& Sue, H.J. (2008). Influence of Surface Roughness and Contact Load on Friction Coefficient and Scratch Behavior of Thermoplastic Olefins. Appl Surf Sci, 254, 4494-9. https://doi. org/10.1016/j.apsusc.2008.01.067.

19. Sedlaček, M., Podgornik, B., \& Vižintin, J. (2009). Influence of Surface Preparation on Roughness Parameters, Friction and Wear. Wear, 266, 482-7. https://doi.org/10.1016/j. wear.2008.04.017.

20. Ivković, B., Djurdjanović, M., \& Stamenković, D. (2000). The Influence of the Contact Surface Roughness on the Static Friction Coefficient. Tribol Ind, 22, 41-4.

21. Ambekar, A.G. (2007). Mechanism and Machine Theory. Eastern Ec. New Delhi: Prentice-Hall of India Private Limited.

22. Kim, H.Y., Lee, H.J., \& Kang, B.H. (2002). Sliding of Liquid Drops Down an Inclined Solid Surface. J Colloid Interface Sci, 247, 372-80. https://doi.org/10.1006/ jcis.2001.8156.

23. Kumar, V., \& Gupta, P. (2012). Importance of Statistical Measures in Digital Image Processing. Int $J$ Emerg Technol Adv, 2, 56-62.

24. Motoyoshi, I., Nishida, S., Sharan, L., \& Adelson, E.H. (2007). Image Statistics and the Perception of Surface Qualities. Nature, 447, 206-9. https://doi.org/10.1038/ nature 05724 . 